DOI: 10.2478/eurodl-2014-0023

\title{
ACCREDITATION OF MOOCS
}

\author{
David Pundak.[dpundak@gmail.com], Kinneret College, ORT Braude College \\ [bttp://www.kinneret.ac.il/Web/En/Default.aspx], \\ NissimSabag[nsabag@hotufi.net], Elena Trotskovsky[elenatro@braude.ac.il], Ort Braude College, Israel
}

\begin{abstract}
Higher education institutions face conflicting challenges; they must equip students with up-to-date knowledge in fields in which knowledge is constantly being renewed, while they also need to guide students to examine reality through broad-based observation and consider different scientific disciplines. They operate within different constrictions such as: learning program boundaries, budgetary constrictions, and lack of accessibility to experts in different areas, and the range of courses offered to students is limited. To cope with these constrictions, Ort Braude Academic College of Engineering opened an experimental program. As part of this program, students were allowed to study MOOC courses under the college's supervision, and were eligible for accreditation if they completed the courses successfully. Only 15 out of the 600 students offered the program, registered for these courses. Only seven were accepted for the program. This paper describes the background for the college's decision, the registration process and supervision of students, detailing students' challenges and achievements in the MOOC courses. Students who completed the MOOC courses reported that they enjoyed meaningful learning, requiring serious efforts in comparison to the courses that the MOOC courses replaced. Given this positive feedback by the students, it was decided to continue with the experiment.
\end{abstract}

\section{Background}

MOOC (Massive Open Online Courses) are online courses open to large audiences. They are provided free of charge through the Internet. The courses are developed by instructors from leading world academic institutions and managed by consortiums such as Coursera or edX. Learning in these courses is assisted by various learning materials: books, video lectures, interactive models, different software programs etc. In the MOOC courses, emphasis is given to social learning or "connectivism" through forums. Discussions are conducted on the forums and the students' contribution to the progress of the discussions is evaluated. There are various types of evaluation in these courses and much difference between them. For example: evaluation may rely on: weekly assignments, contributions to collaborative discussions, peer evaluation, task performance. The courses last for different periods of time from a few weeks (4-6 weeks) to a full semester (12-14 weeks). Students register for the courses on the consortium site several weeks before the courses begin. Each course includes a detailed description of the course contents and this allows the student interested in studying the course to judge the extent of the course's suitability for their goals. A student that complies with the course requirements receives a certificate from the instructor responsible for the development of the course. This certificate does not constitute an academic credit point.

For the second semester of the academic year 2013/2014, the academic college of engineering authorized an invitation to college students to replace a general course they needed to study with a MOOC course in order to receive academic credit. According to the program 20 of those 
students who applied for this experiment would be accepted (see the program below). The experiment aimed to investigate the learning methods of the MOOC courses, the difficulties involved in the learning process, and the students' ability to persevere and complete the course requirements. A coordinator was appointed for the program, to follow-up on: the students' learning during their studies, their activities in the different courses, to assess the level of their learning and decide on the award of academic credits for their learning in the courses. The program's implementation stimulated many questions regarding both the learning processes and the supervision process and evaluation of learning products. To cope with these questions research was conducted to follow-up on the students and the program coordination.

\section{Pedagogy of the MOOC courses}

The tested MOOC courses belonged to leading sites (Coursera, edX, OpenupED, Udacity, FutureLearn) (see Figure 1 below). The pedagogy in these courses relies on a mix of: video lectures, reading materials, assignments that test understanding of the studied subject matter and discussion groups that allow students to raise questions during the course. The video lectures are usually short, lasting 5-15 minutes, but there are also long lectures lasting up to an hour or more. In many cases, questions appear during the lectures, to test the students' comprehension of the issues discussed in the lecture. Usually, once a week, a large assignment is given to test deeper understanding of the studied subject matter. Learning in the MOOC courses relies on the assumption of learning towards mastery, in other words the learner can go back over the studied materials and tests several times to improve their achievements in the weekly assignment (Daniel, 2012).

\section{Provider distribution}

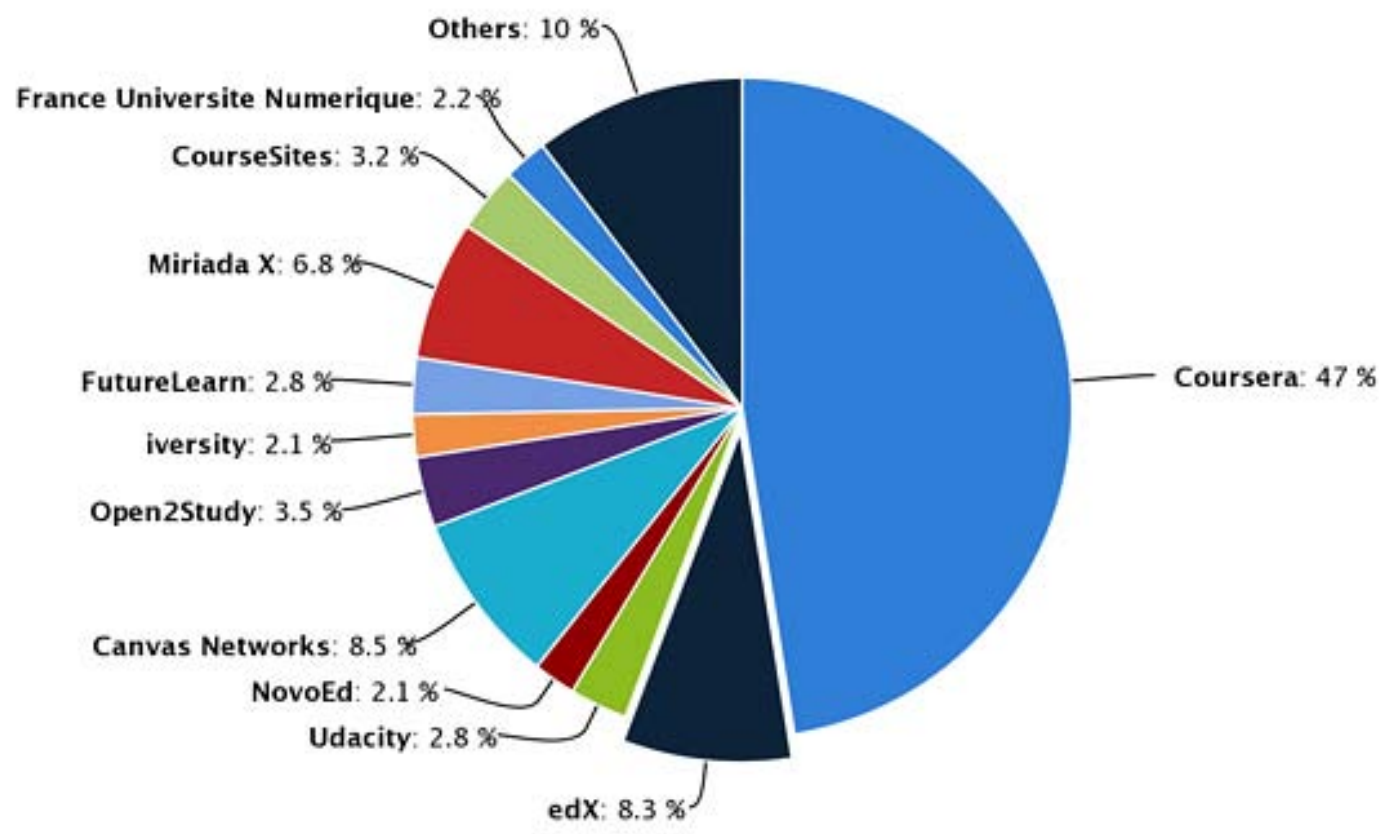

Figure 1. The relative proportion of $\mathrm{MOOC}$ course providers, according to percentage of courses offered by their sites, end of 2013 (source: Shah, 2013)

Typically, thousands (sometimes even tens of thousands) of students participate in MOOC courses. Each course is managed by a restricted number of staff, usually including a chief lecturer and 2-3 teaching assistants, whose job is primarily to answer students' questions or to respond to difficulties arising from their learning during the course. Most of the feedback given to students 
is pre-planned automatic feedback provided by the course staff. In order to encourage debate concerning the course, group discussions are offered in which the students ask questions, suggest ideas or voice opinions relating to different issues linked to the course. Deep dialog often ensues in these discussions, helping students to determine their attitudes concerning the ideas that the course tries to stimulate. The teaching assistants or course lecturer often intervene in the discussion groups in order to point up additional directions of thought, to cope with prevalent mistakes, or to refocus the discussion on the major issues that were under discussion after it has diverted to marginal or irrelevant issues. Further evidence of the importance of social interaction revolving around MOOC course learning is the students' autonomous organization for a particular course as a social network community, in which additional discussion is conducted in parallel to the discussions on the course site.

MOOC courses are usually characterized by a strict timetable. Students wishing to complete the course successfully have to submit a weekly assignment relating to that week's subject matter. After the dateline for submission the assignment cannot be resubmitted. If the MOOC course takes place in parallel to a face-to-face course in the institution that created the MOOC, the timetable does not allow for changes. Sometimes, MOOC courses allow for a personal pace and the student can submit assignments until they have successfully completed them. This flexibility may harm the credibility of the learning and is not suitable for those who tend to procrastinate.

\section{Evaluation of learning in MOOC courses}

One of the serious challenges facing the managers of a MOOC course is the evaluation of the learning of each of the thousands of students studying the course. Evaluation of learning in these courses is conducted with various tools, we relate here to three of them:

1. Automatic examination of closed questions

2. Peer evaluation

3. Examination through artificial intelligence

In many courses, a weekly question is given, for which answers are prepared ahead of time by the course lecturer and staff. These are questions of various sorts: multi-choice, correct/incorrect, fill in a blank, a numerical question or mathematical expression. The automatic system compares the student's response with the question in light of the correct solution and gives immediate feedback to the student. Usually the student is given several opportunities to answer these questions.

Often the students in MOOC courses are asked to respond to an open assignment, which is examined by peers. In order to allow students to examine the assignment in a fair, trustworthy and assertive manner, a rubric needs to be developed, in which each component of the assignment is awarded a predetermined value that is known to the students before performing the assignment. Aided by the rubric and several detailed examples given to students after the dateline for performance of the assignment, the students are asked to evaluate the work of their colleagues on the course. Thus the burden of examining open assignments is placed firmly on the students' shoulders and the course staff simply manages this process. This process yields additional advantages for the students: they are exposed to other ways of thinking expressed by other students on the course, and examining their peers contributes to the creation of a community of learners, who exchange views and deliberate on the way to evaluate products. Additionally the students become active and influence the course in contrast to the automatic examination system in which the student receives a "machine response" (Cheng, 2014). Dispute concerning peer examination relates to the following issues: extent of its trustworthiness and validity, the influence on creativity, the quality of students' feedback in contrast to the teaching 
assistant's response, mental pressure that peer evaluation engenders for students, the influence of students' evasion of peer evaluation.

In certain MOOC courses the answers to subjects discussed can be evaluated with artificial intelligence. The use of the system relies on analysis of feedback given to the students by an expert or the course lecturer. The program learns the rules of evaluation and then uses them on the students' work (Hatiba, 2014). In this way the students on the course can receive immediate feedback, and as a result they can resubmit the assignments for the system's examination. This method of analysis of answers is known as "robo-grading". Its most significant advantage is the scope of its capability to conduct the examination that can reach 16,000 answers in 20 seconds. Although this method has been found to be valid and reliable, there are still some situations in which good evaluations are given to answers that lack internal logic (Perrin, 2013).

Finally we note that there is still a lack of consensus concerning the methods used to evaluate students in MOOC courses. A broad-based study conducted by DeBoer et al. (2014), of 150,000 students in MOOC courses, raised doubts concerning the pedagogic practice and evaluation of students in MOOC courses and consequently also with regard to the ability to evaluate their achievements at the end of these courses.

\section{MOOC courses as a way to broaden and update education}

Students studying in higher education institutions often focus on professional knowledge in a narrow area. Moreover, if an area with practical technological aspects is involved, knowledge is liable to become rapidly outdated. These constrictions stimulate two main questions: how can these institutions vary and enrich the students' academic knowledge of subjects which are outside their field of specialization? How can graduates' professional knowledge be updated in domains of knowledge that are continuously developing and being renewed? (Olsson, 2014)

\section{Subject distribution}

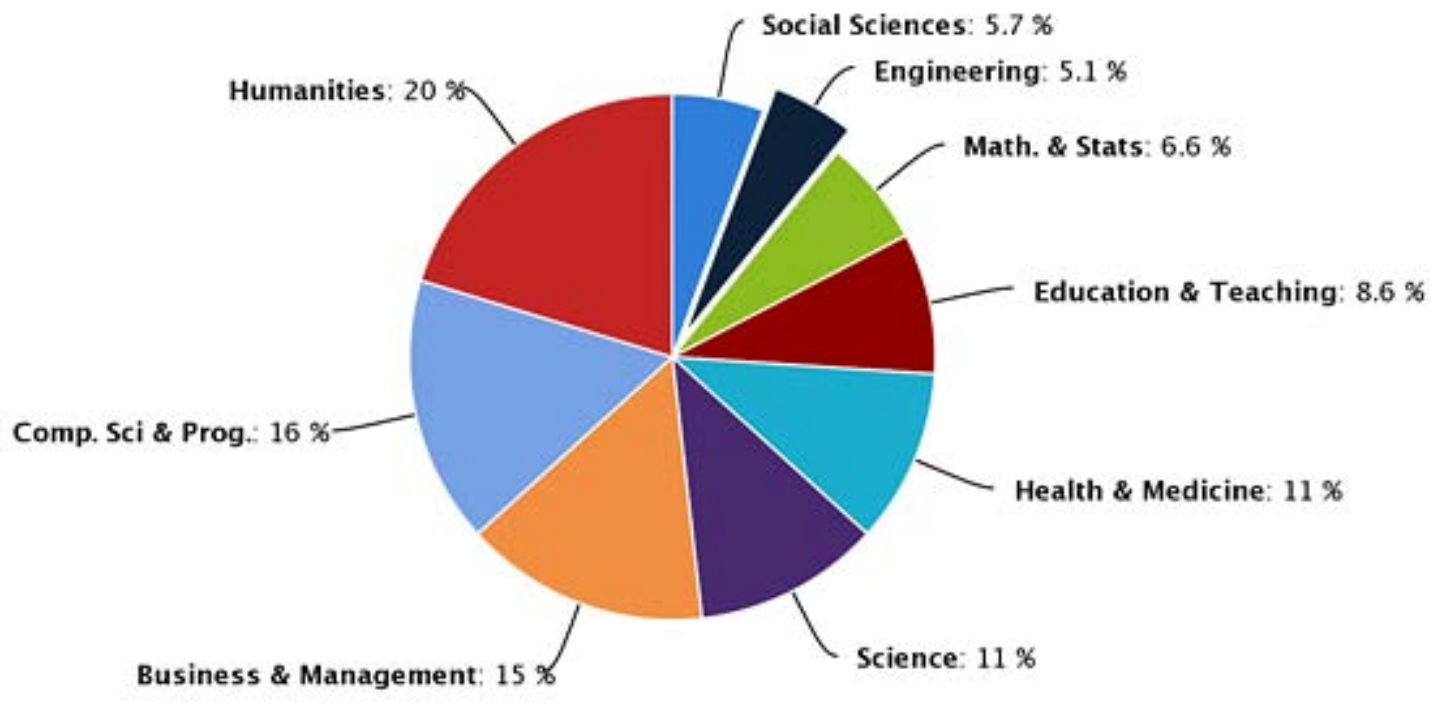

Figure 2. Proportional division of the $\mathrm{MOOC}$ courses by subject, provided by the suppliers of these courses (\%) (Source: Shah, 2013) 
Alongside the need to improve the academic learning environment of the students as consumers, pressure is put on leading world universities to promote the creation and operation of MOOC courses. The MOOC courses compete with other elite institutions and they need to take care to continually improve their learning environment and update the studied subject material (Norton et al., 2013). This approach may be correct in principle, but higher education institutions attempting to implement it may encounter budgetary difficulties (Yuan \& Powell, 2013). In many cases universities need to improve their reputation, and develop their ability to cooperate with other institutions and to point up achievements in the development of the technology of their teaching.

\section{Advantages and disadvantages of accreditation for MOOC courses}

MOOC courses pose a dilemma for academic institutions. The significant influence of courses accessible free of cost online at different levels raises questions such as: which MOOCs are appropriate for first degree engineering students? How can the academic level of these courses be evaluated? How can the learning process be evaluated? Which learning programs can benefit from the integration of MOOC courses? How can academic credits be awarded for learning in these courses?

MOOC courses have many advantages due to: the manner, in which they are developed, the wide variety, easy accessibility, standard evaluation methods, low costs, high level involvement (Thompson, 2013a, 2013b). In most cases, MOOC courses are produced by prestigious institutions, with a huge investment of manpower, learning technologies, development of teaching methods and follow-up of the learners' progress. MOOC courses broaden the variety of courses that can be offered to students, allowing them to gain assistance from them with significant flexibility to supplement gaps in knowledge or background needed for advanced courses. The direct cost that students pay to the institutions who allow them to study MOOC courses is relatively low. The institution needs to ensure that the students have a suitable level of knowledge and skills to study in the MOOC course.

The disadvantages of introduction of MOOC in the college stems from the large difference in the level of the courses, their duration, evaluation methods and learning methods (Bolkan, 2013). Some MOOC are basic introductory courses that last for a few weeks (4-5 weeks), while other high level courses last 12-14 weeks. Some of these courses rely on two weekly hours' study, while others require up to ten weekly hours study. The level of assignments given in these courses varies from basic multi-choice examinations to complex tasks requiring profound analysis of case-studies. Additionally there is a significant difficulty relating to the reliability of the learning in these courses, and how to ensure that a person who received a certificate for their studies in a MOOC course actually studied it. These courses prepare the students for future learning environments that they will encounter in workplaces, and train them for Life-Long Learning.

The MOOC courses also constitute a threat to lecturers in academic institutions. There is a concern that the integration of these courses may in the future make the jobs of some lecturers superfluous, reduce their status or harm their income. The students' inability to study specific courses in prestigious education institutions may cause some of them to prefer MOOC courses, choosing a similar course to that offered by the academic institute in which they are studying. 


\section{Integration of $\mathrm{MOOC}$ in traditional education institutions}

Several possible models are available for academic institutions that are trying to decide whether and how to integrate MOOC courses in their teaching. We note four of them:

1. Background courses - students are asked to prove their prior knowledge in order to begin an academic course, one of the ways to prove this is to study in an MOOC course.

2. Integrated courses - the course lecturer combines teaching the course in face-to-face meetings with learning in a MOOC course. Studies in the MOOC course constitute a preliminary stage for the lecture and allow the lecturer to focus on more advanced issues of the course. This method has been dubbed "flipped classroom".

3. Replacement course - the educational institution decides to permit learning in selected MOOC courses, whose level is suitable for their own academic level. Thus, learning in the MOOC course may constitute a replacement for learning in a traditional course, but the student must take a final exam in the educational institute in order to gain academic credit.

4. Enrichment - the educational institute allows the students to choose MOOC courses to enrich their learning. The courses selected are authorized in consideration of their academic level. The student learning in the MOOC course must present a certificate on completing the course and prove their mastery of the course contents.

\section{Recognition of MOOC courses as part of the general studies}

As part of an experimental program, the college's students were invited to choose one of the MOOC courses and to present a request to study it as a replacement for one of the college's general courses, in order to gain academic credit points. Those students who accepted the invitation were invited to an acceptance interview that aimed to: familiarize the institute with the student's abilities, authorize the choice of the selected course, and clarify the learning style in the MOOC course and the conditions under which the student would be able to gain academic credit from the college.

In order to gain academic credit the student must complete the following stages:

1. An acceptance interview - in order to authorize the selected course and to test the student's ability to cope with the course. The following conditions are also required: the course lecturer must belong to a respected academic institution; the duration of the requested course should be at least 8 weeks; evaluation methods used in the course enable follow-up of learning.

2. A mid-course interview - intended to follow-up on the learning process. The student is asked to present the assignments and papers performed during the course, to discuss them with the program coordinator, to describe the learning process and their impressions from the activities on the course forum.

3. End of course interview - in which the student presents a certificate proving completion of the course, prepares a presentation summarizing principal issues discussed in the course, and presents one studied issue in depth. This interview takes place before at least two lecturers and concludes with the award of academic credit and a course grade. 


\section{The research population}

Approximately a month before the beginning of the second semester of the academic year 2013/2014 the college students were invited to take part in a general learning program through an MOOC course. The students were asked to complete a questionnaire detailing: their chosen course, their academic studies background, their experience of online courses and their expectations from the course. The students were required to demonstrate a suitable level of command of English and they had to choose an MOOC course that lasted at least eight weeks. 15 students completed the registration questionnaire. Nine of them complied with the threshold requirements and were invited to acceptance interviews and seven were authorized to begin to study within the program. The accepted students chose courses on the following subjects: forensic science, astronomy, psychology, international law, economics, and nuclear reactor technology.

\section{Research Questions}

To examine the suitability of the MOOC courses and decide on their integration we asked the following questions:

1. What are the student's considerations for choosing a MOOC course?

2. To what extent are the student's expectations from the course actually met in practice?

3. Which difficulties are encountered by the student learning in these programs and how do they cope with them?

4. What are the advantages of MOOC courses from the students' point of view?

\section{Method}

The study applied qualitative methodology, which allows the investigation of student opinions and collection of relevant data to answer the research questions. The interviews were recorded and analyzed using the interpretative phenomenological approach described by Smith, Flowers and Larkin (2009).

The main research tools were: a registration questionnaire and open interviews at three stages with the students as detailed below.

\section{Research tools}

1. Registration questionnaire - that the students completed when they registered for the program in response to the formal invitation.

2. Acceptance interview - during the acceptance process interviews were held with the students before they were accepted for the program.

3. Mid-course interview - in the middle of the course and at its end follow-up and summarizing interviews were held to investigate the learning process.

4. Concluding interviews - following the end of the course the students prepared short presentations discussing the main subjects of the MOOC courses they had studied. A committee composed of three lecturers evaluated the quality of their reports and portfolios of their academic work and exams that the students presented during the course and the committee decided on the students' grades for these courses. 


\section{Findings}

\section{Reasons for the choice of MOOC}

The students' gave varied reasons for their choice of the MOOC courses. The main reason was the interest stimulated by the course and the opportunity to study a fascinating subject that it was impossible to study within the framework of the college courses, as is described in the following quote:

\section{M: I want to open a new window to the world of economics that is unfamiliar and therefore} attractive to me

Other reasons stemmed from the course lecturers' characteristics - their background (including their personality) and the unique knowledge that they represented (e.g. financial, irrational human thinking, astronomy), as is evidenced from the quotes below:

\section{K: The privilege to learn from Dan Arieli (Nobel laureate) is my own dream. \\ B: The lecturer is interesting; he has a sense of humour.}

Some of the students had prior knowledge of the subject of the chosen course (work experience in Africa, interest in forensic science, experience with sound quality) and the course offered them supplementary and deeper knowledge on these subjects. An additional reason for their choice was the connection between the course and their hobby (art, music, cooking). The next citation is an example of such a case:

\section{A: I read about it, I expect to enjoy the course and reach deeper understanding concerning the} subject.

\section{Prior knowledge concerning the MOOC content and requirements}

The students registering for the courses had read the course syllabus, listened to an introductory lecture, considered the assignments that awaited them during the course, and assessed the weekly number of hours that they would have to invest in order to succeed in the course. As shown in the following quotes:

\section{M: I know that a weekly exam is one of the course obligations but it does not deter me from taking the course. \\ B: I intend to spend about six - seven hours a week watching the lectures and writing bomework.}

In three cases the students even read about the course lecturer, learning about their academic achievements, and even reading their books.

\section{Expectations from the course}

The students noted various expectations from the course. One student had experience with MOOC and knew which difficulties and benefits could be anticipated. Some expected that they would attain deeper understanding of the studied subjects as follows:

G: I already took three Coursera courses. I recently completed a MOOC course on the Android system. My experience from these courses was good and I would recommend that other people should participate. 
B: (choosing a course in imagining other earths): I expect to know more about the world.

Approximately half saw the course as an opportunity to improve their English. Others wanted to communicate with students in other areas of the world on an interesting subject, or at least to open a window on to a new subject.

\section{B: I intend to communicate with people around the world.}

Some of the students saw the course as an opportunity to reinforce their professional background. In addition, the student $\mathrm{P}$ noted that he hoped that the course would allow him to advance the development of Start-up Company, as he noted in his own words:

\section{P: I wanted to acquire knowledge in "Forensic Science", to widen my horizons and it might}

belp me in directing my "startup".

Students expressed their expectations regarding the learning load in MOOCs in the acceptance questionnaire (pre-test). At the end of course interview (post-test) we asked the students how much time they actually invested in MOOC learning in each of four learning channels: reading course text, watching video lectures, performing assignments and involvement in discussion groups. The results are presented in Figure 3. It seems that even though the students had quite a high estimation of the expected learning load in MOOC, at the end of the course it transpired they had actually invested, on average, about $45 \%$ more time.

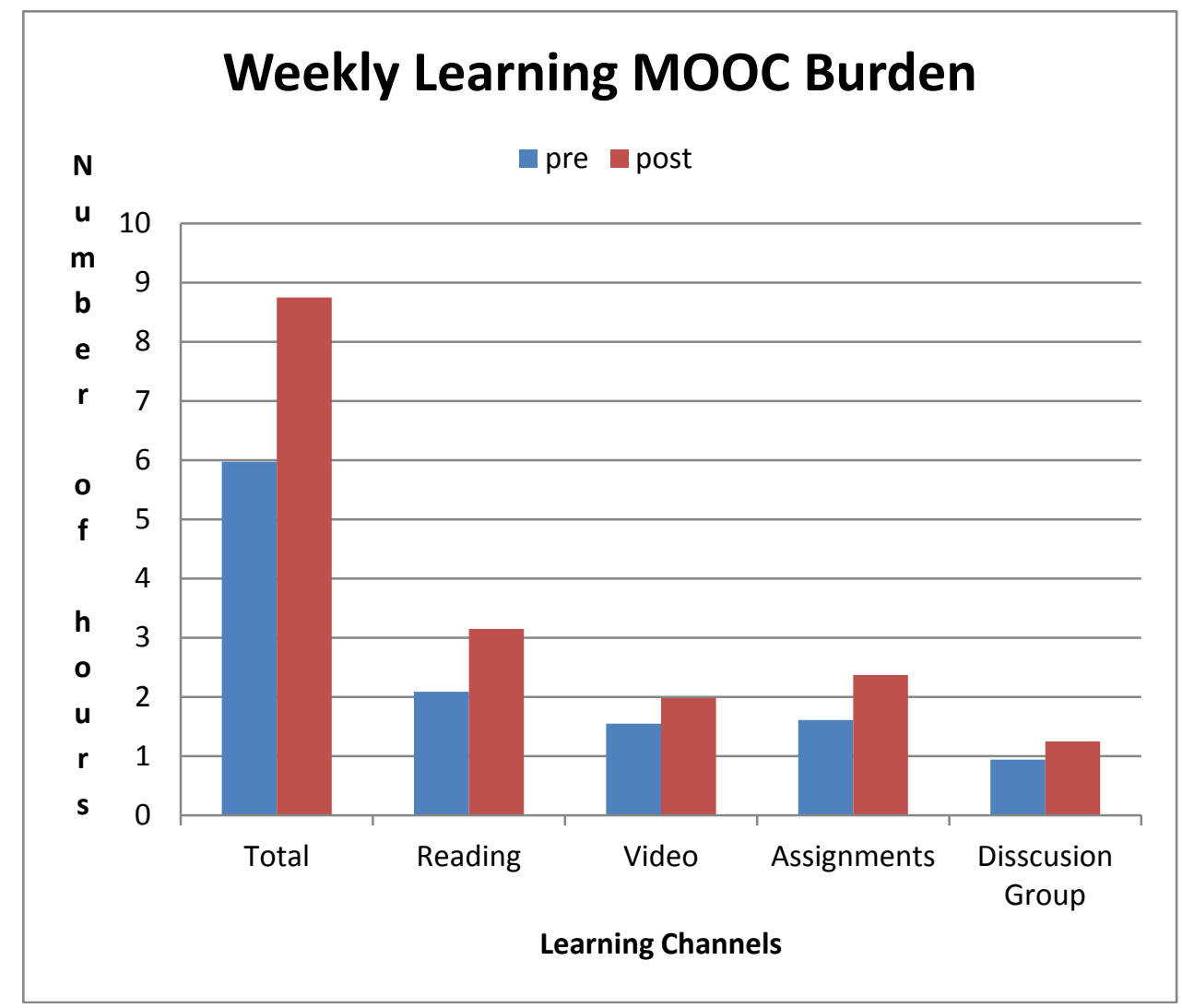

Figure 3. Comparison between students' expectations of learning load from MOOC (pre-test), in weekly hours, and the actual learning load reported at the end of MOOC (post-test) 


\section{Difficulties during studies}

For some of the students, the encounter with the course constituted a very challenging experience; for others the course was suitable. The greatest difficulties with an onerous learning load are described in the following quotes:

$G$ (a course dealing with international crime): The course was not simple, there was a huge amount of learning material, and the extent of reading was as much as 50 pages per lecture. The English was problematic since the course work dealt with legal English including many professional concepts. The Coursera lectures are usually short - 15 minutes, but the lectures in this course were up to an hour long.

$M$ (a course in psychology): I knew that the course would demand a lot of work, but I did not know that the work burden would be so large. The course was very burdensome, if I had known I would not have applied for it. I won't leave because the course is very interesting ... there is no other course in the college that gives the subject so much time.

On the other hand one student noted in the mid-term interview:

$K$ (a course in financial management): until now the course was sufficiently comprehensive and did not go into too many deep details. Where details were required then the subject was clearly presented as I would expect from a course for a broad audience and not particularly for experts in the field. It suited me.

\section{Advantages of the MOOCs}

In the mid-term interview, all the students described the lecturers with appreciative words. A student who spent about 13 study hours a week in her course, which was far more than the time she spent in her regular studies, noted:

K: I invest a lot in this course because of the lecturer's personality and the way he administers the course. I also hope that this course will help me to fulfil my dream to be an organizational advisor.

The student who studied a course on nuclear reactors described his lecturer's mastery:

P: The course lecturer was excellent. He knows how to draw analogies properly, to describe a complex situation simply, to emphasize main points in every subject.

All the students noted that their courses were thorough and interesting. For example:

\section{P: I thought the course will be only fluttering but it was very deep.}

\section{Summary and discussion}

Contrary to our expectations (Kirp, 2013) relatively few students registered for the program only 15 out of 600 students who received the invitation $(2.5 \%)$. This low percentage of applications can be explained in several ways: entry requirements - ability to read and write in English at a high level, online learning that is not customary in the college, a typically heavy burden of studies in engineering courses that does not leave time for the consideration of such a program, fear of an innovative program - "let the innovators go first" (Rogers, 2003). Two main common characteristics were identified among the students who did come to the entrance interviews: ability for verbal expression, good academic achievements $(M=79.0, S D=5.8)$. In other words the MOOC courses offered are usually not in practice relevant for most students; 
rather they attract a small student population with defined characteristics. In the mid-course interviews of the seven students accepted to the program, it was possible to identify a high level commitment to cope with the course contents, seriousness and perseverance to complete the assignments, and strong respect for the course contents. On the other hand some of them criticized the fact that they were flooded with knowledge and felt the requirements for reading were excessive.

The students noted positively that the material studied in the courses was up-to-date. The course dealing with nuclear reactors dealt not only with past catastrophes such as: Chernobyl and Three Mile Island but also with the disaster resulting from the damage to the Fukushima reactor in 2011 due to the earthquake and tsunami waves. In a course dealing with astronomy current NASA space programs were discussed. A course dealing with financial organization reviewed the AIG company predicament during the subprime crisis during 2008-2010. The fact that the courses were up-to-date increased interest and the academic validity of the models offered by these courses. Students noted that the scientific models were applicable both for events in the distant past that they had only heard about and for events in the recent past that they themselves had experienced as adults.

There is a tension in these courses between the burden of studies required and the interest that they stimulate. Complaints about the serious burden in MOOC courses were repeatedly noted by all the students in the program. One of the students noted that it was lucky that he had been dismissed from his work; otherwise he would not have been able to comply with the course requirements. Another student in the program was frustrated by the heavy study burden in a course dealing with international law. The student felt that he did not succeed in gaining the mastery expected from him due to the broad scope of the studied material: an abundance of new terms in long lectures that lasted for an hour or more. In fact he survived the course because of the successful experience that he had had in previous MOOC courses that he had studied on the Android operation system. From these testimonies it appears that there is room to warn students registering for the program about the study burden required in MOOC courses. Students who do not prepare themselves mentally for this work load may drop out of the course as happens with most of those registering for these courses.

In six out of the seven courses chosen by the students in the program, they expressed strong satisfaction regarding the level of the lecturers and the interest that they stimulated. The extent of interest aroused by these courses encouraged three of the students to take additional MOOC courses for different purposes for example: to examine a future learning program, for professional specialization and for general knowledge. It was possible to gain a cautious impression, because of the limited sample, that most of the MOOC courses comply with good standards of online teaching. They succeed in representing the studied subjects in an interesting manner, the subject matter is presented in a suitable way and well supported by lectures and evaluation of the student's studies is conducted fairly, allowing even those learners who are not native English speakers to succeed in these courses.

Until now (July, 2014), six students have completed the MOOC courses. In the final interviews, the students noted the high level of studies in these courses; some were delivered by well-known lecturers and even Nobel Prize winners. Learning took place through exposure to a variety of teaching means: lectures, reading tracts, case studies, examples from reality. Social activity in the discussion groups with other participants was moderate; students usually formed relations with one of the other students on the course and deepened the discussion with that student. The students reported a heavier work load than they had expected, 8-12 hours a week. The grades received by the students in the MOOC courses were very high, above 95 . The college staff that followed the students' progress had the impression that the learning resources invested by the 
students in these courses were significantly greater than those required for traditional elective courses in the college. The students noted that in accordance with the investment in their studies, they had a strong sense of achievement at the end of the courses. They felt a sense of satisfaction that they had been able to demonstrate strong self-discipline, studying without the close social support that they would have had in the college courses. In our estimation it is advisable to continue to examine ways to include MOOC courses in colleges, exploiting their advantages, and to continue to investigate their influence on students' learning methods and on lecturers' teaching methods in the college. All the students who completed the MOOC courses expressed their willingness to share their experience of this learning method with the general college student population.

\section{References}

1. Bolkan, J. (2013). MOOCs Top Open Access for Disruptive Potential. In Campus Technology, Blog, 2013, October 23. Retrieved from:

http://campustechnology.com/articles/2013/10/23/report-moocs-top-open-access-fordisruptive-potential.aspx

2. Cheng, C.Y. (2014). An Exploratory Study of Emotional Affordance of a Massive Open Online Courses. In European Journal of Open, Distance and e-Learning, 17(1), (pp. 43-55). Retrieved from http://www.eurodl.org/materials/contrib/2014/Cheng.pdf

3. Daniel, J. (2012). Making Sense of MOOCs: Musings in a Maze of Myth, Paradox and Possibility. In Journal of Interactive Media in Education, 2012. Retrieved from http://wwwjime.open.ac.uk/jime/article/view/2012-18

4. DeBoer, J.; Ho, A.D.; Stump, G.S.; Breslow, L. (2014). Changing "Course”: Reconceptualizing Educational Variables for Massive Open Online Courses. In Educational Researcher, 43(2), (pp. 74-84).

5. Hatiba, N. (2014). The tsunami of MOOC courses: Will they induce an overall revolution in teaching, learning and higher education institutions? In Teaching in the Academy, 4, (pp. 40-64). Retrieved from http://www.academicteaching.net [Hebrew]

6. Kirp, D.L. (2013). Tech mania goes to college: Are MOOCs - massive open online courses the utopia of affordable higher education, or just the latest fad? In The Nation, Blog, 2013, September 23. Retrieved from: http://www.thenation.com/article/176037/tech-mania-goescollege\#axzz2g2HzfG5t

7. Lewin, T. (2013). Colleges adapt online courses to ease burden. In The New York Times, 29 April 2013. Retrieved from: http://www.nytimes.com/2013/04/30/education/collegesadapt-online-courses-to-ease-burden.html

8. Norton, A.; Sonnemann, J.; McGannon, C. (2013). The online evolution: when technology meets tradition in higher education. Grattan Institute Report No. 2013-3, April 2013. Retrieved from: http://grattan.edu.au/wp-content/uploads/2014/04/186_online_higher_education.pdf

9. Olsson, U. (2014). A preliminary Exploration of Operating Models of Second Cycle/Research Led Open Education Involving Industry Collaboration. In European Journal of Open, Distance and e-Learning, 17(1), (pp. 76-92). Retrieved from http://www.eurodl.org/materials/contrib/2014/Olsson.pdf

10. Perrin, D. (2013). Robo-Grading and Writing Instruction: Will the Truth Set Us Free? In English Journal, 102(6), (pp.104-106). Retrieved from:

http://www.ncte.org/library/NCTEFiles/Resources/Journals/EJ/1026jul2013/EJ1026Robo.pdf

11. Rogers, E. (2003). Diffusion of innovation (5th Ed). Free Press, New York

European Journal of Open, Distance and e-Learning - Vol. 17 / No. 2 
12. Shah, D. (2013). MOOCs in 2013: Breaking Down the Numbers. In edSurge, Blog. Retrieved from: https://www.edsurge.com/n/2013-12-22-moocs-in-2013-breaking-down-the-numbers

13. Smith, J.A.; Flowers, P.; Larkin, M. (2009). Interpretative phenomenological analysis: Theory, method and research. Sage.

14. Thompson, G. (2013a). A MOOC Platform Based on Engagement. In Campus Technology, Blog, 2013, November 06. Retrieved from:

http://campustechnology.com/articles/2013/11/06/a-mooc-platform-based-onengagement.aspx

15. Thompson, G. (2013b). Can MOOCs Replace Traditional Textbooks? In Campus Technology, Blog, 2013, December 04. Retrieved from:

http:/ / campustechnology.com/articles/2013/12/04/can-moocs-replace-traditionaltextbooks.aspx

16. Yuan, L.; Powell, S. (2013). MOOCs and Open Education: Implications for Higher Education. JISC CETIS. Cetis publications - publications from the Centre for Educational Technology, Interoperability and Standards. Retrieved from: http://publications.cetis.ac.uk/2013/667 